\title{
Copeptin, a marker of vasopressin, decreases significantly in early state after bariatric surgery
}

\section{Recep Aktimur ${ }^{1}$, Turkan Mete ${ }^{2,}$ Suleyman Cetinkunar ${ }^{3}$, Mehmet Yaman ${ }^{4}$, Osman Beton ${ }^{5}$}

Emre Avci ${ }^{6}$, Hasan Erdem ${ }^{3}$, Kadir Yildirim ${ }^{1}$

${ }^{1}$ Ministry of Health, Samsun Training and Research Hospital, Department of General Surgery, Samsun, ${ }^{2}$ Ministry of Health, Samsun Training and Research Hospital Department of Endocrinology and Metabolism, Samsun,

${ }^{3}$ Adana Numune Training and Research Hospital, Department of General Surgery, Adana, ${ }^{4}$ Ministry of Health, Samsun Training and Research Hospital Department of Cardiology, Samsun, ${ }^{5}$ Department of Cardiology, Cumhuriyet University Faculty of Medicine, Sivas, ${ }^{6}$ Hitit University Department of Biology/Biochemistry, Faculty of Science and Arts, Çorum

\section{OBJECTIVES}

Copeptin, the C-terminal fragment of arginine vasopressin pro-hormone, has been associated with the metabolic syndrome (MetS), diabetes mellitus (DM) development [1,2]. Bariatric surgery is the method proven to cause significant weight loss in morbid obesity treatment. Hormonal changes in addition to weight loss with restrictive and/or malabsorptive methods contribute to regression of metabolic syndrome. Although decreased ghrelin level, increased peptide Y level, increased glucagon like peptide-1 (GLP-1) and cholecystokinin level after obesity surgery are known [3,4] no previous study has evaluated its effect on copeptin levels.

The aim of our study is to evaluate preoperative and postoperative alterations of copeptin in patients who underwent obesity surgery and evaluate any differences between sleeve gastrectomy (SG) and mini gastric bypass (MGB) in terms of copeptin levels.

\section{METHODS}

Twenty five consecutive patients, who were treated for morbid obesity by SG or MGB, between March and April 2015 were included in this study. Diagnosis of MetS was made according to NCEP ATP-III criteria. Blood samples were obtained from patients preoperatively and one month after operation. ELISA technique was used to measure copeptin level in plasma samples.

\section{RESULTS}

SG and MGB were applied to 11 and 14 patients, respectively. Mean ages $(35 \pm 8.3$ vs. $34.7 \pm 7.7, p=0.908)$ and body mass indexes of the two groups were similar $(44.3 \pm 2.3$ vs $44.2 \pm 3.2, p=0.948)$. Mean preoperative copeptin levels of patients who had SG $(0,715 \pm 0,619 \mathrm{ng} / \mathrm{ml})$ and MGB $(0,577 \pm 0,222 \mathrm{ng} / \mathrm{ml})$ were similar $(p=0.003)$. At postoperative $1^{\text {st }}$ month mean weight loss of the patients was $12.4 \mathrm{~kg}$. Postoperative copeptin levels were statistically significantly decreased in both groups compared with preoperative levels (SG; $0,628 \pm 0,610 \mathrm{ng} / \mathrm{ml}$, $p=0,03$, MGB; $0,474 \pm 0,180 \mathrm{ng} / \mathrm{ml}, p=0,01$ ). Decrease in copeptin level was higher in mini gastric bypass group than sleeve gastrectomy group but this didn't reach statistical significance (Table 1).

Table 1. Pre and postoperative copeptin levels according to type of the operation.

\begin{tabular}{|l|l|l|l|}
\hline & Preop Copeptin (ng/ml) & Postop Copeptin (ng/ml) & $\mathrm{p}$ value \\
\hline Sleeve gastrectomy, $\mathrm{n}=11$ & $0,715 \pm 0,619$ & $0,628 \pm 0,610$ & 0.003 \\
\hline Mini gastric bypass, $\mathrm{n}=14$ & $0,577 \pm 0,222$ & $0,474 \pm 0,180$ & 0.001 \\
\hline $\mathrm{p}$ value & 0.446 & 0.377 & \\
\hline
\end{tabular}

\section{CONCLUSIONS}

Recent studies have demonstrated the association between copeptin level and DM and MetS. Our study is the first one to show that copeptin significantly decrease during early postoperative period after obesity surgery. Decrease in copeptin level achieved by bariatric surgery may be one of the reasons of glycemic regulation and improvement in MetS parameters before achievement of target weight in these patients. Encouraging results we achieved with limited number of patients may form a basis for studies that will show progression of copeptin levels in patients who had bariatric surgery with larger samples and longer follow up periods.

\section{REFERENCES:}

1. Fenske W, Wanner C, Allolio B, Drechsler C, Blouin K, Lilienthal J, et al. Copeptin levels associate with cardiovascular events in patients with ESRD and type 2 diabetes mellitus. J Am Soc Nephrol. 22, 782-90 (2011)

2. Meijer E, Bakker SJL, Halbesma N, de Jong PE, Struck J, Gansevoort RT. Copeptin, a surrogate marker of vasopressin, is associated with microalbuminuria in a large population cohort. Kidney Int. 77, 29-36 (2010)

3. Cummings DE, Weigle DS, Frayo RS, Breen PA, Ma MK, Dellinger EP, et al. Plasma ghrelin levels after diet-induced weight loss or gastric bypass surgery. N Engl J Med. 346, 1623-30 (2002).

4. Korner J, Bessler M, Cirilo LJ, Conwell IM, Daud A, Restuccia NL, et al. Effects of Roux-en-Y gastric bypass surgery on fasting and postprandial concentrations of plasma ghrelin, peptide YY, and insulin. J Clin Endocrinol Metab. 90, 359-65 (2005) 